\title{
Application of Google Docs in English for Specific Purposes Collaborative Writing
}

\author{
Nam Quang Pham ${ }^{1^{*}} \quad$ Lien My Tran ${ }^{2}$ Chau Thi Minh Do ${ }^{3}$ Hien Thi Thanh Dao ${ }^{4}$ \\ Phong Thanh Nguyen 5 \\ Department of Foreign Languages, University of Medicine and Pharmacy at Ho Chi Minh City, \\ 217 Hong Bang Street, District 5, Ho Chi Minh City, Vietnam
}

\begin{abstract}
English language learners today have considerable opportunities to practice their writing skill via their peer interaction in Web 2.0 platforms, such as Blogs, Wikis, and Google Docs. Different studies have investigated the influence of these platforms on student writing collaboration and interaction, but few studies had explored factors that may affect English for Specific Purposes (ESP) student collaborative writing in Vietnamese settings. This study, therefore, attempts to explore the impact of four factors, namely gender, student attitudes towards learning English, student economic status, and availability of English at home on Google Docs-based interaction and collaborative writing outcome at a southern university in Vietnam. Fifty participants took part in this study and they worked collaboratively in small groups in Google Docs to finish two writing tasks and complete a survey afterwards. Analysis of their survey, interaction, and writing outcome suggests that gender, student attitudes towards learning English, and the number of books available at their homes have an impact on their writing outcome whereas their economic status did not seemingly affect their writing quality. Some pertinent pedagogical implications are also discussed in this paper.
\end{abstract}

Keywords: Google Docs, collaborative writing, English for Specific Purposes

DOI: $10.7176 / \mathrm{JLLL} / 78-02$

Publication date: April $30^{\text {th }} 2021$

\section{Introduction}

With the development of Web 2.0 platforms, language learners have more opportunities to practice collaborative writing than before. Numerous studies (Lee, 2010; Wichadee, 2010; Hadjerrouit, 2011; Woo, Chu, Ho \& Li, 2011; Kessler, Bikowski \& Boggs, 2012; Domalewska, 2014; Shukor, 2014; Suwantarathip \& Wichadee, 2014; Farrah, 2015; Li \& Kim, 2016) have explored this topic in different contexts and reported interesting data points. However, to explore in what ways Web 2.0 tools can facilitate collaborative writing, we need to diversify learning contexts (Storch, 2013) and explore different factors that may influence their collaboration and writing products. Unfortunately, although these studies have reported the use of wikis for collaborative writing (Storch, 2013), not many researchers have conducted inquiries on the application of Google Docs in English language writing. Specifically, there is scant research in Google Docs-based collaborative writing in Vietnam. To contribute to research diversity in this area, this study aims to explore four factors that are likely to affect English as a Foreign Language (EFL) student participation, interaction and writing quality in their completion of two collaborative writing tasks using Google Docs.

\section{Literature Review \\ Potential benefits of Web 2.0}

Some potential benefits of Web 2.0 in second language teaching have been discovered in some recent studies. First, it can promote learning through enhancing students' motivation and providing stimulus to change their attitudes and perceptions (Luo, 2013). Kessler (2009) also maintains that Web 2.0 may afford a safe and interactive environment where students were willing and able to work collaboratively and autonomously. In addition, Web 2.0 has the capacity of bringing students into a learning community where they can have easy access to each other and further foster a sense of community and belonging through social interaction (Lee, 2011). Ducate and Lomicka (2008) support the use of Web 2.0 when they acknowledge that blogging can improve students' reading skills when they participate in a research-based project. Furthermore, writing blogs can enhance learners' autonomy, as writing freely on blogs gives students more control of their own learning rather than restricting them to practice language skills (Lee, 2011). Thanks to these potential benefits, pre-service teachers should be trained to become competent of both using and incorporating 2.0 technology into their instruction. Hence, it is necessary for this course to cover theories, principles and strategies of using technology in education.

\section{Potential benefits of online collaborative writing in Web 2.0 platforms}

Some previous studies have also shown the potential benefits of having students practice writing collaboratively in the online environment. In Karchmer's (2001) study, thirteen teachers were discussing their attempts to 
redefine the literacy for the digital environment. These teachers recognized that "students' motivation to produce quality work increased when they knew it would be published on the Internet. Access to a worldwide audience provided a purpose to writing, one that inspired students to invest more time in their assignments." (Karchmer, 2001, p. 458). For this reason, Karchmer maintained that the teachers should develop online collaborative projects and global exchanges and stress the importance of online publishing due to the high motivational element for students. Choi (2008) listed some advantages of online collaboration in ESL context. First, it will create an active environment for new relationships in ESL writing classrooms. Second, online collaboration will improve students' writing skills in that "good writing can be made possible by creating a sense of audience/community in writing, attaching importance to feedback and revision, reducing stress of writing and enhancing mutual help" (p. 35). In addition, online collaboration will cultivate a sense of audience which can motivate students' consideration of the interests, needs and language level of their readers in the writing process. Finally, online collaboration can enhance the importance of feedback and revision. Students can improve their linguistic knowledge and understand more about the skills of writing as a result of receiving feedback. Peer response can enhance the sense and the need for revision and lead to better quality of work. In the most recent study, Li and Kim (2016) successfully investigated students' patterns of interactions in the online collaborative writing tasks. Specifically, the authors examined the dynamic change of language functions when students completed their writing tasks. Moreover, various types of scaffolding strategies were clearly discussed. This study has examined the online writing process in a comprehensive manner, thus shed a new light in research in second language writing. Through the study, the researchers have shown the diverse approaches that students took when they worked on two writing tasks on wikis. Drawing from the concepts of mutuality and equality, students' different patterns of interactions in online environment were insightfully investigated. Taken these studies together, it has come to our mind that although online collaborative writing can facilitate students' completion of tasks, it does not automatically lead to participants' "taking collaborative approach" (Li and Kim, 2016, p. 39). A variety of external factors, such as students' backgrounds, attitudes towards learning English, gender and so forth need to be thoroughly considered by the instructors before second language learners can collaborate for their online writing tasks. Unfortunately, not many previous studies have explored the complex relationship among students' writing outcome, gender, attitudes towards learning English, economic status, language book availability when they work together to complete Google Docs-based collaborative writing tasks in ESP settings. To address this gap in research literature, this study aims to answer the following research question:

To what extent do students' gender, attitudes towards learning English, economic status and language book availability affect their Google Docs-based collaborative writing outcome?

\section{Hypotheses}

Gender seems to play a critical role in the process of Google Docs-based collaboration. There is a common belief that female students tend to perform better than male students in language learning. Therefore, this study will focus on this factor. The hypothesis for this variable is that female students will have higher scores than male students when completing collaborative writing tasks. Although the factor of gender is believed to affect students' learning language outcomes, it is important to consider other factors. Students' attitude towards English is another factor that needs to be considered. If a student has positive attitude towards learning English, will it have an impact on Google Docs-based writing collaboration? This study will assess the level of positive attitude towards learning English. Therefore, students' attitude towards learning English will be the second variable to be considered and its hypothesis is that if students have more positive attitudes towards learning English, they will have higher scores when completing collaborative writing tasks. The next factor to be considered is students' economic status. This factor is worth considering because it is outside classrooms and the school system has no control on it. It can be interesting to see if students' economic status has a big or small impact on Google Docs-based writing collaboration. Therefore, the hypothesis for this variable is that if students' family has more economic advantages, they will have better scores for the Google Docs-based collaborative tasks. Additionally, the availability of books in students' home can be another important factor that needs to be considered. It is assumed that the more books are available in students' homes, the higher their command of English becomes. Therefore, the hypothesis for this variable is that if students have more language practice books at home, they will achieve higher scores for Google Docs-based collaborative tasks.

\section{Methodology}

This study centers on five variables - gender, attitudes towards learning English, the number of available textbooks for learning English, students' economic status, and their English scores - that may affect student interaction when they collaborate with peers to complete writing tasks. 


\section{Study participants}

This study was conducted on 50 study participants ( 25 males and 25 females) who were mainstream medical students at a southern university in Vietnam. These students were chosen at random in an ESP course in Fall 2020 semester and was divided into 18 groups. Table 1 represent the gender and number of members per group.

Table 1: Group information

\begin{tabular}{|l|l|l|}
\hline \multicolumn{1}{|c|}{ Groups } & \multicolumn{1}{|c|}{ Gender } & \multicolumn{1}{c|}{ Number of members per group } \\
\hline $1 \rightarrow 7$ & male & 3 \\
\hline $8 \rightarrow 9$ & male & 2 \\
\hline $10 \rightarrow 16$ & female & 3 \\
\hline $17 \rightarrow 18$ & female & 2 \\
\hline
\end{tabular}

Their participation in this study was completely voluntary. Each participant was explained in their native language about the purpose of the study and asked to sign the consent form before data collection.

\section{Study procedures}

After all consent forms were signed and collected, the research team created a Google Docs page for each group and invited group members to complete two writing tasks. The first writing task asks participants to reflect their opinion about free insurance for Vietnamese citizens while the second task requires students to write a medical report for an imaginary patient. To complete these tasks successfully, study participants had to use Google Docs to discuss with their group members for ideas, to enter writing texts, to proofread and revise their peers' writing, and to format their final writing product.

When all groups submitted their final writing products, each study participant were asked to complete a survey that aims to explore some factors such as gender, attitudes towards learning English, families' economic background, and the number of language practice books available at homes that may affect their interaction patterns in Google Docs. The information from this survey will be used for examining the independent variables. When the students completed their surveys, the research teams holistically assessed their Google Docs-based collaborative writing products. Each research team member evaluated and rated a writing product with a score ranging from 0 to 25 , depending on its quality. The research team then compared the scores for each writing product and any discrepancies among raters were resolved through discussion. At the end of this grading process, each group had two scores and the average of these scores was calculated and then became the score that each group member achieved after their writing collaboration. This score was used for examining the dependent variables.

\section{Dependent variable}

The dependent variable is the scores for the writing products that study participants completed after their collaboration with peers in Google Docs. These scores are calculated by taking the average of the scores of two collaborative writing tasks within each group. Each writing task was assessed in five criteria: task achievement, coherence and cohesion, lexical resources, grammatical range and accuracy, and overall quality, each of which was worth five points. For instance, Group 1 had three members: John, Alex, and Matt (pseudonym) who achieved 20 points for writing task 1 and 18 points for writing task 2 . The average of these scores is 19 and each of these three students earned 19 points for their collaborative work. The overall score for each student ranged from $0-25$.

\section{Independent variables}

There are four independent variables in this study: gender, attitudes towards learning English, families' economic status and numbers of books in students' homes.

The variable of gender appears as "Gender" in SAS analysis and is coded as "1" for male students and " 2 " for female students in the dataset. The variable of students' attitude towards learning English appears as "Attitudes" in SAS analysis and is calculated by each student's response to the question: "Do you think that learning English is very important for your future career?" Students can answer this question by choosing a number on a 4-point scale.

The meaning of each point is shown in Table 2 below.

Table 2: Meaning of each response to Do you think that learning English is very important for your future career?

\begin{tabular}{|l|l|l|l|l|}
\hline Point & $\mathbf{1}$ & $\mathbf{2}$ & $\mathbf{3}$ & $\mathbf{4}$ \\
\hline Meaning & Strongly disagree & Disagree & Agree & Strongly agree \\
\hline
\end{tabular}

The variable of students' economic status examines the relationship between the economic condition of a student's family and its impact on his or her learning English. This variable is examined because learning English can be quite expensive for university students in Vietnam when they have to manage supplementary materials, tuitions if taking extra courses to have more language practice and so forth. This variable appears as "Economy" in SAS analysis and is calculated by each student's response to the question: "Which economic 
group do you think that your family belongs to?" Their responses to this question are guaranteed to be kept confidential so that they can provide the most accurate information. Students can answer this question by choosing a number on a 4-point scale. The meaning of each point is shown in Table 3 below.

Table 3: Meaning of each response to Which economic group do you think that your family belongs to?

\begin{tabular}{|l|l|l|l|l|}
\hline Point & $\mathbf{1}$ & $\mathbf{2}$ & $\mathbf{3}$ & $\mathbf{4}$ \\
\hline Meaning & $\begin{array}{l}\text { Very economically } \\
\text { disadvantaged }\end{array}$ & $\begin{array}{l}\text { Economically } \\
\text { disadvantaged }\end{array}$ & $\begin{array}{l}\text { Economically } \\
\text { advantaged }\end{array}$ & $\begin{array}{l}\text { Highly economically } \\
\text { advantaged }\end{array}$ \\
\hline
\end{tabular}

The variable of book availability examines the relationship between the number of language practice books in students' homes and its impact on learning English. This variable appears as "Books" in SAS analysis and is calculated by each student's response to the question: "Approximately how many English language practice books are available in your home?" Students can answer this question by choose a number on a 5-point scale. The meaning of each point is shown in Table 4 below.

Table 4: Meaning of each response to Approximately how many English language practice books are available in your home?

\begin{tabular}{|l|l|l|l|l|l|}
\hline Point & $\mathbf{1}$ & $\mathbf{2}$ & $\mathbf{3}$ & $\mathbf{4}$ & $\mathbf{5}$ \\
\hline Meaning & None or very few & $5-10$ & $11-15$ & $15-20$ & More than 20 \\
\hline
\end{tabular}

\section{Hypothesis}

It is expected that study participants' collaborative writing outcomes are affected by the gender, the number of books at their homes, their attitudes towards learning English, and their families' economic condition. The multiple regression method is used to predict effects from such independent variables. The correlation between the dependent and independent variables are also examined to see the direction and the strength of their relationships. There are two null hypotheses to be tested in this project. The first null hypothesis is that the population coefficient of determination equals to zero, meaning that the variance in students' scores cannot be predicted from the set of independent variables. The second null hypothesis is that the regression slope of each predictor equals to zero, indicating that the dependent variable cannot be predicted by those independent variables.

\section{Results}

After the research teams evaluated all writing products and participants' responses to the four independent variables were collected, the results were entered into the SAS application. The outcome of the F-test for population coefficient of determination in Table 1 shows that the $p$-value is smaller than $.05(p<.0001)$. Therefore, the first null hypothesis $\left(\mathrm{H}_{0}: \rho^{2}=0\right)$ is rejected, meaning that the set of independent variables can predict some portion of the dependent variable (students' score). The value of R-Square of 0.6867 from the regression procedure indicates that nearly $69 \%$ of the variance in students' score can be predicted from this regression model. Table 5 displays the results of analysis of variance.

Table 5: Analysis of variance

\begin{tabular}{|l|l|l|l|l|l|}
\hline Source & DF & Sum of squares & Mean square & F-Value & Pr $>$ F \\
\hline Model & 4 & 100.27183 & 25.06796 & 24.66 & $<.0001$ \\
\hline Error & 45 & 45.74817 & 1.01663 & & \\
\hline Corrected Total & 49 & 146.02000 & & & \\
\hline R-Square & 0.6867 & & & \\
\hline
\end{tabular}

The output of the t-test for regression slope in Table 2 indicates the rejection of all null hypotheses for partial regression slopes of the set of independent variables because their p-value is smaller than .05. It can be stated that all independent variables have significant effects on students' score at $95 \%$ confidence (alpha $=.05$ ). The regression equation for participants' writing outcome can be displayed in Table 6 below.

"Predicted Writing Outcome $=18.42252+0.82830$ Gender +0.46547 Attitudes -0.39540 Economy + 0.86693 Books"

Table 6: Parameter estimates

\begin{tabular}{|l|l|l|l|l|}
\hline Variable & DF & Parameter estimate & t value & Pr $>|\mathbf{t}|$ \\
\hline Intercept & 1 & 18.42252 & 17.27 & $<.0001$ \\
\hline Gender & 1 & 0.82830 & 2.86 & 0.0064 \\
\hline Attitudes & 1 & 0.46547 & 2.37 & 0.0223 \\
\hline Economy & 1 & -0.39540 & -2.29 & 0.0265 \\
\hline Books & 1 & 0.86693 & 4.62 & $<.0001$ \\
\hline
\end{tabular}

The partial regression slope of the variable "gender" is 0.82830 , suggesting that given one unit change in gender, participants' writing outcome is predicted to change 0.82830 while holding other independent variables constant. The partial regression slope of the variable "attitudes" is 0.46547 , indicating that given one unit change 
in student's attitudes towards learning English, we expect to see a change of 0.46547 in participants' writing outcome, while holding the rest of predictors constant. The partial regression slope of the variable "economy" is -0.39540 , meaning that the predicted value of participants' writing outcome will increase 0.39540 , given one unit decrease in the economic condition of students' family, while other independents are held constant. The participants' writing outcome also changes with a value of 0.86693 , given one unit change in the availability of language books in students' home, while holding the rest of predictors constant.

\section{Discussion and Implication}

This study focuses on four different factors and the results have shown that these factors have significant effects on the interaction and writing outcome when a group of 50 students at a southern university Vietnam attempted to complete two collaborative writing tasks in Google Docs.

The correlation between gender and writing outcome is 0.24577 and it shows a difference in learning English between male and female students. The strong, negative correlation of between students' economic status and their writing outcome is also interesting because it is contrary to the common belief that students with advantaged economic condition will learn better than those with disadvantaged one. The correlation value between them has shown that participants with higher economic status-those who are economically advantageous - achieved lower scores for their writing tasks. The correlation between participants' writing outcome versus their attitudes and the number of books available at homes is 0.47872 and 0.75512 respectively. These figures denote a strong and positive correlation and suggest that students with more positive attitudes and more practice books at home achieved better results in their collaborative writing tasks.

Given the fact that gender, student attitudes towards learning English, and book availability at home may impact their collaborative writing outcome, classroom teachers may consider cultivating the importance of learning English in general and writing academic English specifically before placing them into collaborative writing groups. In addition, there is a difference in the writing quality between male and female students. Therefore, classroom teachers should also pay attention to this factor when they design and conduct writing tasks. Male students may need more support and instruction from their instructors than female students. Last but not least, students should be encouraged to read English language books at home to broaden their knowledge of grammatical structures and vocabulary, thus improve their overall writing quality.

\section{Limitations}

It is also important to note that the R-Square value is 0.6867 , meaning that the variables examined in this study can only account for about $68.67 \%$ of the overall scores among these 50 students. Future research can investigate what other variables can be used to predict students' performance in completing collaborative writing tasks in Google Docs.

\section{References}

Choi, J. W. (2008). The role of online collaboration in promoting ESL writing. English Language Teaching, 1(1), $34-49$.

Domalewska, D. (2014). Technology-supported classroom for collaborative learning: Blogging in the foreign language classroom. International Journal of Education and Development using Information and Communication Technology, 10(4), $21-30$.

Ducate, L. C., \& Lomicka, L. L. (2008). Adventures in the blogosphere: From blog readers to blog writers. Computer Assisted Language Learning, 21(1), 9-28.

Farrah, M. A. H. (2015). Online collaborative writing: Students' perception. Journal of Creative Practices in Language Learning and Teaching, 2(2), $17-32$.

Hadjerrouit, S. (2011). A collaborative writing approach to wikis: Design, implementation, and evaluation. Issues in Informing Science and Information Technology, 8, 431 - 449.

Karchmer, R. A. (2001). The journey ahead: Thirteen teachers report how the internet influences literacy and literacy instruction in their K-12 classrooms. Reading Research Quarterly, 36(4), 442 - 466.

Kessler, G. (2009). Student-initiated attention to form in wiki-based collaborative writing. Language Learning \& Technology, 13(1), $79-95$.

Kessler, G., Bikowski, D., Boggs, J. (2012). Collaborative writing among second language learners in academic web-based projects. Language Learning \& Technology, 16(1), 91 - 109.

Lee, L. (2010). Exploring wiki-mediated collaborative writing: A case-study in an elementary Spanish course. CALICO Journal, 27(2), $260-276$.

Lee, L. (2011). Blogging: Promoting learner autonomy and intercultural competence through study abroad. Language Learning \& Technology, 15(3), 87 - 109.

Li, M. \& Kim, D. (2016) One wiki, two groups: Dynamic interactions across ESL collaborative writing tasks. Journal of Second Language Writing, 31, 25 - 42. 
Li, M., Kim, D. (2016). One wiki, two group: Dynamic interactions across ESL collaborative writing tasks. Journal of Second Language Writing, 31, 25 - 42.

Luo, T. (2013). Web 2.0 for language learning: Benefits and challenges for educators. International Journal of Computer-Assisted Language Learning and Teaching, 3(3), 1 - 17.

Shukor, S. S. (2014). Effects of Facebook collaborative writing groups on ESL undergraduates' writing performance. International Journal of English Language Education, 2(2), 89 - 99.

Storch, N. (2013). Collaborative writing in L2 classrooms: New perspective on language and education. Tonawanda, NY: Multilingual Matters.

Suwantarathip, O., Wichadee, S. (2014). The effects of collaborative writing activity using Google Docs on students' writing abilities. The Turkish Online Journal of Educational Technology, 13(2), 148 - 156.

Wichadee, S. (2010). Using wikis to develop summary writing abilities of students in an EFL class. Journal of College Teaching \& Learning, 7(12), 5 - 10.

Woo, M., Chu, S., Ho, A., Li, X. (2011). Using a wiki to scaffold primary-school students' collaborative writing. Educational Technology \& Society, 14(1), 43 - 54. 